\title{
Penerapan Knowledge Management Sistem Informasi Penjaminan Mutu Fakultas Berbasis Web Di FTI-UKWS
}

\author{
William Christopher ${ }^{1}$, Indrastanti Ratna Widiasari2
}

\begin{abstract}
${ }^{1}$ Information Technology Departement, Satya Wacana Christian University, Salatiga, Idnonesia Email: 1672016287@student.uksw.edu,2indrastanti.widiasari@uksw.edu.
\end{abstract}

\begin{abstract}
Abstrak
Teknologi informasi merupakan salah satu aset dari perusahaan maupun organisasi yang penting untuk perkembanganya, dengan perkembangan teknologi pada jaman sekarang yang sangat pesat menjadikan teknologi harus selalu diperbaharui. Salah satu peranan teknologi informasi adalah penerapan knowledge management. Knowledge Management merupakan sistem yang mampu meningkatkan serta mengelola suatu informasi pengetahuan pada perusahaan atau instansi yang menerapkan knowledge management. Pada penelitian ini, berfokus pada menerapkan knowledge management system pada Penjaminan Mutu Fakultas di Universitas Kristen Satya Wacana. Penelitian ini didasari karena dari lembaga PMF masih menggunakan cara manual dalam pengarsipan data, untuk mengatasi hal itu maka tujuan dari penelitian ini adalah untuk merancang aplikasi web yang berguna untuk pengarsipan data PMF agar lebih efektif dan efesien. Dalam penelitian ini menerapkan KMS (Knowledge Management System), dan menggunakan metode Knowledge Management System Life Cycle yang terdiri dari beberapa proses tahapan yang terdiri mulai dari evaluasi infrastruktur, analisis desain KMS dan pengembangan, serta evaluasi pada tahap akhir. Hasil dari penelitian ini berupa aplikasi web pengarsipan data yang berguna bagi PMF yang diharapkan agar PMF lebih efesien dalam pengarsipan data.
\end{abstract}

Kata Kunci: Aplikasi Web, Knowledge, Management System

\section{PENDAHULUAN}

Perkembangan Ilmu Pengetahuan dan Teknologi pada jaman sekarang sangat pesat dan banyak perubahan di berbagai bidang mulai dari bidang pendidikan, pertanian, bisnis, pemerintahan. Bedasarkan data dari EGDI (E-Government Development Index) yang di cantumkan oleh Peserikatan Bangsa Bangsa (PBB). Bedasarkan survey tahun 2016 Indonesia berada di posisi 116 turun 10 peringkat dari posisi tahun 2014 yaitu di posisi 106 [1]. Bedasarkan data tersebut Indonesia sekarang masih jauh dari kata yang diharapkan salah satu contohnya adalah pengelolaan Sistem Informasi dan Teknologi informasi terbatas. Dalam penelitian ini, peneliti mengambil studi kasus di Fakultas Teknologi Informasi Universitas Kristen Satya Wacana Salatiga.

This work is licensed under a Creative Commons Attribution 4.0 International License. 
FTI-UKSW mempunyai sebuah lembaga yang bergerak untuk menjaga mutu dan audit internal FTI-UKSW yang bernama PMF (Penjaminan Mutu Fakultas). Lembaga Penjaminan Mutu Fakultas (PMF) adalah sebuah lembaga yang memiliki kewajiban untuk meningkatkan mutu dan kualitas pendidikan secara terus menerus dan berkelanjutan. PMF ini didirikan tahun 2016 dengan mempunyai tugas dan tanggung jawab. Salah satu contoh tanggung jawab anggota PMF seperti mengikuti rapat dan melakukan evaluasi internal (Kesesuaian pengajaran dosen, kepuasan mahasiswa, dll), kemudian mendampingi dan menjelaskan aktifitas Penjaminan Mutu pada saat visitasi BAN-PT untuk akreditasi, bersama-sama menyusun dan memperbaiki instrumen di PMF, bersama-sama menetapkan sasaran mutu PMF, serta bekerjasama dengan Kaprogdi untuk mengevaluasi mutu masing-masing progdi. Selain mempunyai Tanggung jawab tersebut, PMF juga memilik tugas yang harus dilakukan yaitu melakukan evaluasi Pembelajaran Semester, melakukan absensi dosen luar dan dalam untuk analisis kesesuaian pengajarannya, mengagendakan dan membuat notulen rapat PMF, membuat laporan kerja anggota PMF, serta mengelola dokumen kerja PMF. Menurut Oakland (1993,p.5) menyatakan bahwa "Quality is used to signify 'excelence' of a product or service". Mutu digunakan untuk menunjukkan keunggulan " dari sebuah produk atau jasa. Suatu produk atau jasa dikatakan bermutu apabila mempunyai keunggulan dibanding produk atau jasa yang lain [2].

Penjaminan Mutu Fakultas sampai saat ini masih dilakukan secara manual dalam pengelolaan arsip dokumen. Hal tersebut mengakibatkan sering terjadi kesulitan dalam mendapatkan dokumen, lebih banyak memakan waktu, serta rentan dalam kehilangan data sehingga turunnya kualitas pelayanan di PMF. Dengan adanya penelitian ini, peneliti akan merancang aplikasi web dengan sistem informasi yang berguna agar membantu kinerja PMF serta diharapkan PMF bisa lebih efisien waktu, dan mempermudah orang untuk mengakses dokumen dari PMF.

Perlunya pengelolaan Pengetahuan yang ada di PMF agar semua dokumen bisa dikelola dengan baik dengan menerapakan konsep Knowledge Management System (KMS) yang berbasis sistem informasi pada PMF sehingga dapat meningkatkan kualitas pelayanan. KMS merupakan sebuah tools yang berbasis sistem informasi yang digunakan oleh banyak instansi ataupun perusahaan untuk mengelola dokumentasi berupa pengetahuan atau knowledge, serta informasi penting yang dimiliki oleh anggota di dalam sebuah instansi atau perusahaan[3]. Penerapan KMS ini begitu dibutuhkan karena KMS merupakan pendekatan yang sistematis dan juga terencana penerapan knowledge management terjamin, sekaligus gagasan, inovasi, serta pemikiran dengan begitu organisasi bisa berjalan dengan efektif dan efesien [4]. Dengan menerapkan konsep KMS, agar dapat menghimpun dan mengelola semua pengetahuan yang ada di Lembaga PMF dengan cara membangun Knowlegde, menghimpun, menyimpan dan menggunakannya agar Lembaga PMF lebih transparan dan akuntable sehingga meningkatkan layanan 
pada Lembaga PMF. Tujuan mengelola knowledge yang ada pada PMF ini adalah agar organisasi mampu mengelola staf mereka. Salah satu tujuan dari knowledge management adalah bagaimana orang-orang dari berbagai tempat yang berbeda mulai saling bicara, yang sekarang populer dengan label learning organization, yaitu organisasi yang memfasilitasi proses pembelajaran bagi seluruh anggota organisasi secara berkelanjutan [5]. Knowledge management system didefinisikan sebagai sistem yang dikembangkan untuk mendukung dan meningkatkan proses organisasi dalam hal penciptaan, penyimpanan, pengampilan, distribusi dan aplikasi pengetahuan [6].

Penerapan KMS merupakan suatu cara bagi Lembaga PMF untuk mengidentifikasi, membuat, mempresentasikan, mendistribusikan, dan memungkinkan pengadaptasian wawasan dan pengalaman yang terdiri dari pengetahuan, baik yang dimiliki oleh personal maupun yang melekat pada proses atau standar prosedur pelayanan yang mempunyai tujuan utama untuk mengelola dan mentransfer suatu dokumen dengan efektif untuk meningkatkan kualitas pelayanan yang ada pada Lembaga PMF [7]. Karena KMS dapat memudahkan pencarian informasi dengan efesien, KMS juga dapat meningkatkan proses pengambilan keputusan, serta dapat meningkatkan efesiensi proses bisnis organisasi seperti PMF. Maka dari itu cara yang digunakan dalam penelitian ini melibatkan knowledge management system [8]. Dalam penelitian sebelumnya membahas bagaimana mengembangkan knowledge management dalam bentuk aplikasi dekstop berbasis web di PT. Gamatechno Indonesia Aplikasi digunakan untuk membantu dan mempermudah pengolahan data dokumentasi seperti dokumentasi produk, dokumentasi rapat dan dokumentasi pelatihan. Selain itu aplikasi ini dapat membantu karyawan IT dalam membuat menyimpan data log problem dan karyawan IT dapat dengan mudah mencari dan mengunduh dokumentasi [9].

Dalam penelitian lain "Penerapan Knowledge Management System Berbasis Informasi Desa Untuk Meningkatkan Layanan Publik Desa Dukuh Karya" membahas tentang bagaimana cara mengelola dan menerapakan knowledge management system yang ada pada desa Dukuh Karya berupa sistem informasi desa berbasis web. Sistem informasi ini berguna dalam meningkatkan layanan publik, serta membuat pemerintah desa lebih transparan dan akuntable [10]. Pada penelitian berikutnya yang berjudul "Penerapan Knowledge Management System (KMS) Berbasis Web Studi Kasus Bagian Teknisi dan Jaringan Fakultas Ilmu Komputer Universitas Sriwijaya" mengatakan bahwa pentingnya mengelola data dan informasi secara terstruktur di Fakultas Ilmu Komputer Universitas Sriwijaya. Penelitian ini menggunakan metodologi yang mengacu pada knowledge management system. Dalam metodologi ini terdapat 4 langkah utama yaitu persiapan dan evaluasi infrastruktur, analisis dan desain knowledge management, pengembangan knowledge management dan evaluasi [11]. 
Vol. 3, No. 1, March 2021

p-ISSN: 2656-5935 http://journal-isi.org/index.php/isi $\quad$ e-ISSN: 2656-4882

\section{METODE}

Metode penelitian yang dilakukan dalam mengembangkan aplikasi dengan metode Knowledge Management System Life Cycle (KMSLC) ditunjukkan pada Gambar 2.

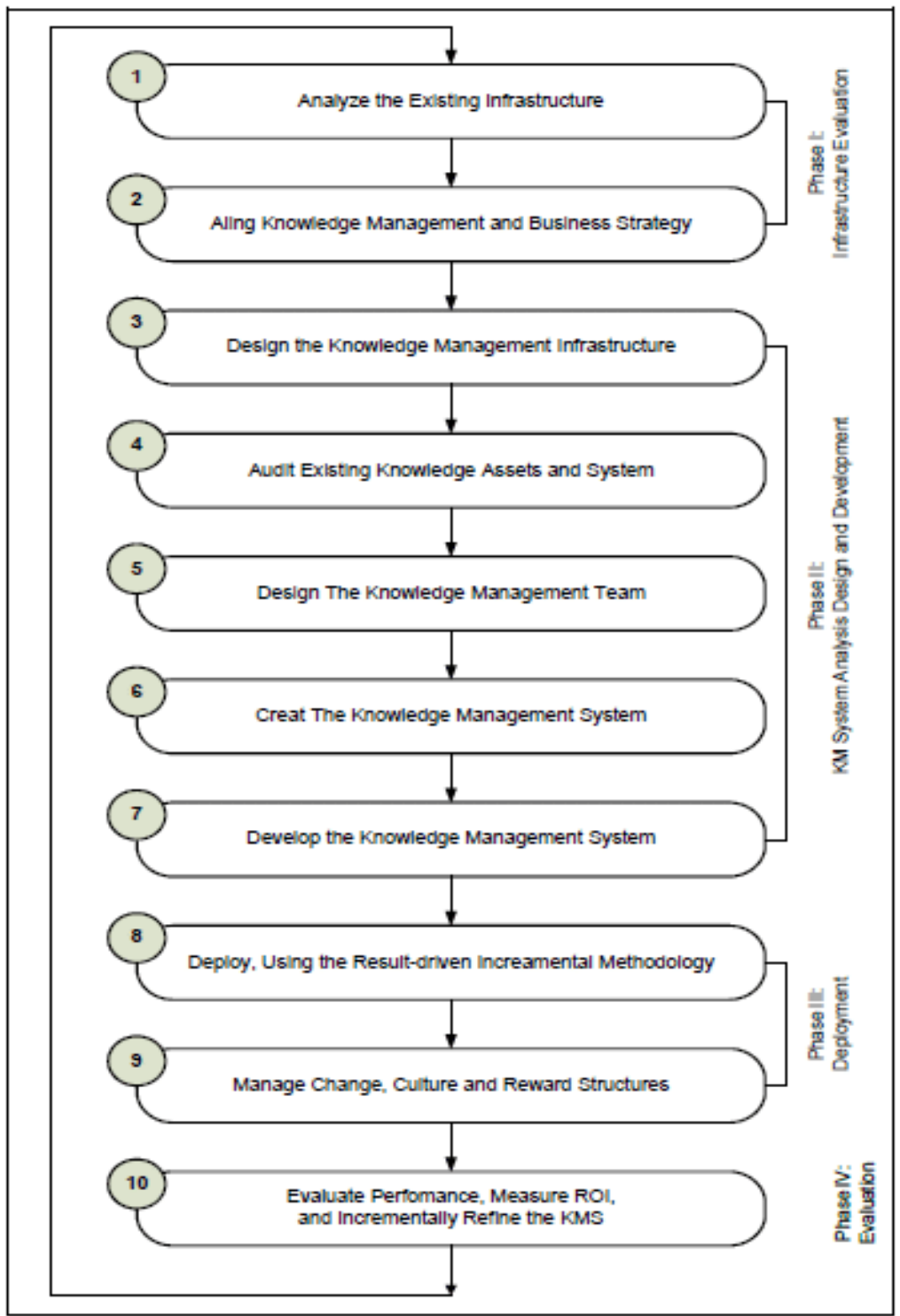

Gambar 1 Tahap Penelitian[11] 
Pada tahap infrastructure evaluation akan mengkaji prasarana yang ada di Penjaminan Mutu Fakultas (PMF FTI-UKSW) dan menyesuaikan knowledge management dengan stratetegi sehingga akan menghasilkan knowledge management yang sesuai dengan tujuan organisasi.

1. Analyze the Exizting Infrastructure

Langkah pertama dilakukan dengan cara melakukan analisis pada infrastruktur yang ada di Penjaminan Mutu Fakultas serta menghitung apa saja yang terdapat pada PMF, dari situ dapat diidentifikasi ketidak simetrisan dari prasarana yang ada.

2. Alling Knowledge Management and Business Strategy

Setelah melakukan analisis, langkah berikutnya melakukan wawancara dengan salah satu pihak PMF untuk mengetahui proses bisnis yang ada serta dapat menentukan model knowledge management yang sesuai, kemudian menganalisis data-data yang didapatkan dalam proses wawancara, kemudian melakukan pemilihan data yang diperlukan.

Pada langkah selanjutnya, KM system analysis design and development penelaah akan mendesain prasarana, melakukan audit terhadap aset pengetahuan dan sistem yang tersedia[12]. Selanjutnya akan membangun Knowledge Management berbasis Sistem Informasi penjaminan mutu Fakultas (PMF FTI-UKSW).

1. Design the Knowldege Management Infrastructure

Langkah pertama dilakukan menentukan jenis sistem dan aset-aset apa saja yang diperlukan untuk pembuatan KMS, kemudian dapat membuat elemen yang diperlukan untuk menyusun knowledge management system di PMF

2. Audit the Existing Knowledge Assets and System

Kemudian, pada langkah selanjutnya melakukan audit terhadap aset-aset yang ada pada PMF untuk di analisis agar dapat menilai kelayakan aset knowledge yang ada pada PMF, kemudian dapat menentukan pembuatan knowledge managemnt system yang tepat bagi PMF

3. Design the Knowledge Management System

Langkah selanjutnya, membuat desain dari rancangan Knowledge Management System yang akan dibuat, agar rancangan sistem yang dibuat dapat sesuai dengan harapan dari PMF. Dalam langkah ini dibuat membuat class diagram serta activity diagram. Kemudian membuat rancangan database.

4. Creat The Knowledge Management System

Setelah membuat desain dari rancangan KMS, langkah berikutnya membangun KMS dengan cara membuat database terlebih dahulu kemudian melakukan relasi data, setelah itu dilanjutkan pembuatan sistem knowledge management yang diperlukan. 
5. Develop the Knowledge Management System

Kemudian langkah berikutnya, menerjemahkan desain sistem yang telah dibuat kedalam bahasa pemrograman. Pada langkah ini difokuskan pada pembuatan sistem sesuai dengan desain yang sudah dibuat

Pada tahap deployment penelaah akan menguji coba system pada lingkungan yang sesungguhnya. Memanage perubahan struktur karena adanya system yang baru dari manual menjadi teknologi, supaya knowledge dapat beradaptasi dan berinteraksi dengan system yang baru.

1. Deploy, Using the result-driven increamental Methodology

Dalam langkah ini, melakukan uji coba penerapan KMS yang telah dibuat mulai dari user interface, input data, input dari setiap menu, kemudian diuji secara keseluruhan

2. Manage Change, Culture and Rewsards Structure

Langkah selanjutnya, melakukan perubahan dari uji yang sudah dilakukan pada langkah sebelumnya, hal ini dikarenakan adanya sistem baru yang juga memicu terjadinya pergeseran budaya dari yang awalnya input manual mejadi sebuah teknologi. Hal ini dilakukan agar nantinya knowledge management system yang dibuat dapat beradaptasi dengan sistem sebelumnya.

Pada tahap evaluation, penelaah akan menguji performance system yang baru dan meningkatkan KMS yang berguna bagi organisasi. Evaluate Performance, Measure ROI, and Increamentally Refine the KMS Langkah terakhir, melakukan evaluasi hasil implementasi KMS yang telah dibuat, setelah itu melakukan analisa terhadap hasil evaluasi, hal ini dilakukan dengan cara membandingkan kebutuhan user dengan analisis dan desain dari KMS.

\section{HASIL DAN PEMBAHASAN}

\subsection{Infrastructure Evaluation}

Menganalisa sarana dan prasarana di Lembaga PMF FTI UKSW pada bidang Teknologi lebih banyak menggunakan konsep sederhana dengan menggunakan media kertas atau menggunakan aplikasi microsoft, adanya sistem dokumentasi yang masih manual menyebabkan sulitnya mencari data-data yang diperlukan karena banyaknya dokumentasi yang tidak terstruktur sehingga memakan waktu yang lama mengakibatkan menurun nya kepuasan pelayananan. 
Vol. 3, No. 1, March 2021

p-ISSN: 2656-5935 http://journal-isi.org/index.php/isi

e-ISSN: 2656-4882

Menyelaraskan knowledge management dengan strategi bisnis tahapan selanjutnya yang harus dilakukan. Dengan adanya prasarana yang kurang memadai berdampak pada proses pelayanan terutama pada penggunaan waktu yang lama dan proses pencarian data data semakin membutuhkan waktu. Hal ini mengakibatkan adanya keluhan tentang informasi dan pelayanan di lembaga ini.

\subsection{KM system analysis, design, and development}

Proses desain bertujuan untuk merancang atau membuat suatu aplikasi. Hal ini meliputi perancangan antarmuka aplikasi. Desain menggunakan UML yang terdiri dari use case diagram, class diagram, activity diagram dan sequence diagram. Berikut merupakan use case diagram dari sistem yang dikembangkan.

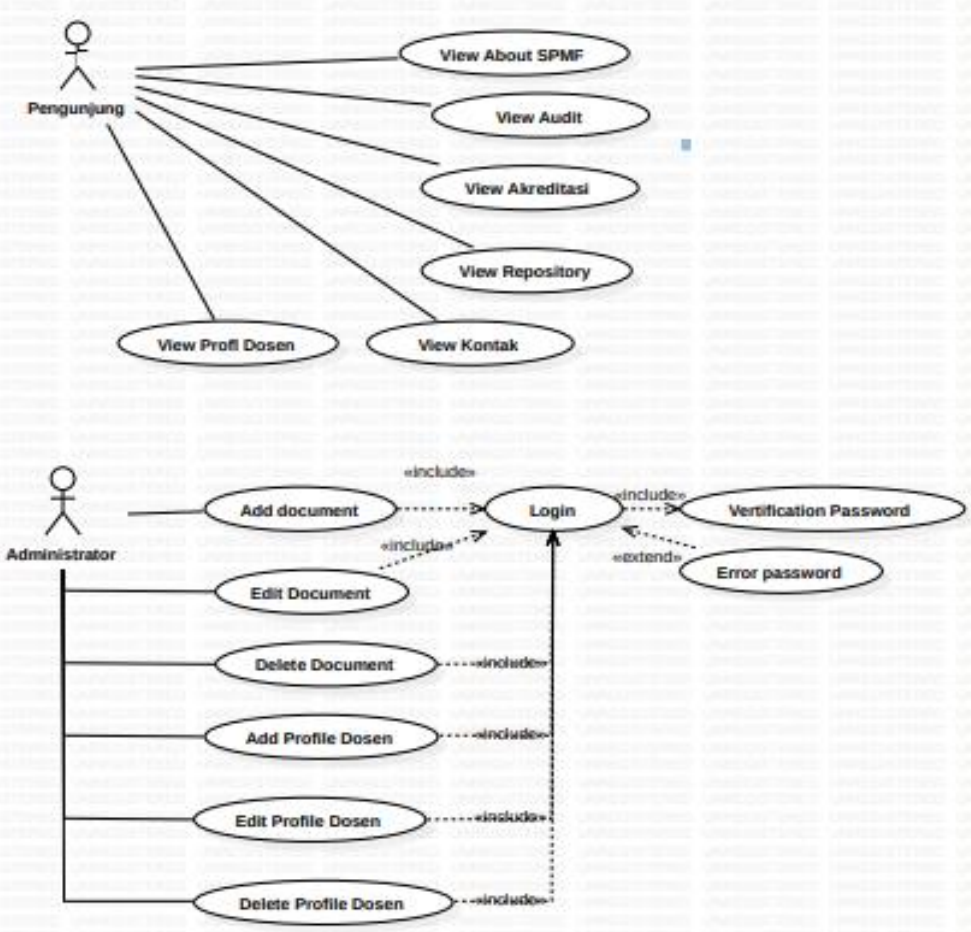

Gambar 2. Use case diagram

Pada inti dalam pembangunan sistem yaitu, Pengunjung dapat melihat informasi dan dapat mengunduh dokumen yang ada dalam penjaminan mutu. Admin harus melakukan Login untuk dapat mengedit, menghapus,atau menambahkan informasi yang ada dalam web. 


\subsection{Deployment}

Implementasi dari proses yang melibatkan pengetahuan setiap individu baik masyarakat dan petugas Lembaga PMF FTI UKSW serta proses pelayanan petugas kepada warga, permintaan dokumen kepada PMF, Informasi terbaru dari FTI UKSW Sehingga perlu dibuatkan media yang bisa mengakomodir kebutuhan tersebut. Perancangan user interface yang user friendly untuk mempermudah dalam implementasi knowledge management menjadi familiar dan membantu dalam kegiatan tersebut. Web ini dibagi menjadi 2 akses yaitu admin dan user. Dimana Admin bertugas dalam mengelola dokumen, dan menjadi editor pada Web tersebut. Sedangkan User hanya dapat melihat informasi pada web tersebut dan mengunduh dokumen yang ada pada web tersebut.

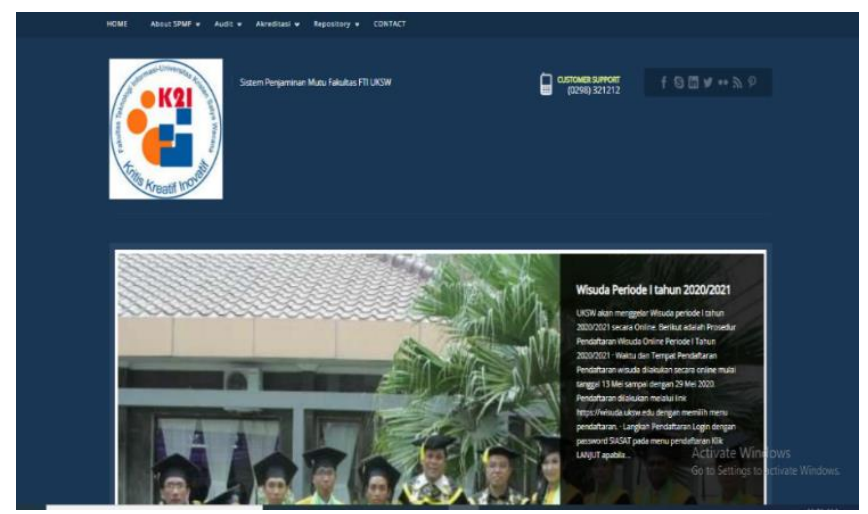

Gambar 3. Tampilan web

Pada Gambar 3 merupakan tampilan awal user. Tampilan awal user terdapat menu Home, About PMF, Audit, Akreditasi, Repository, dan Contact.

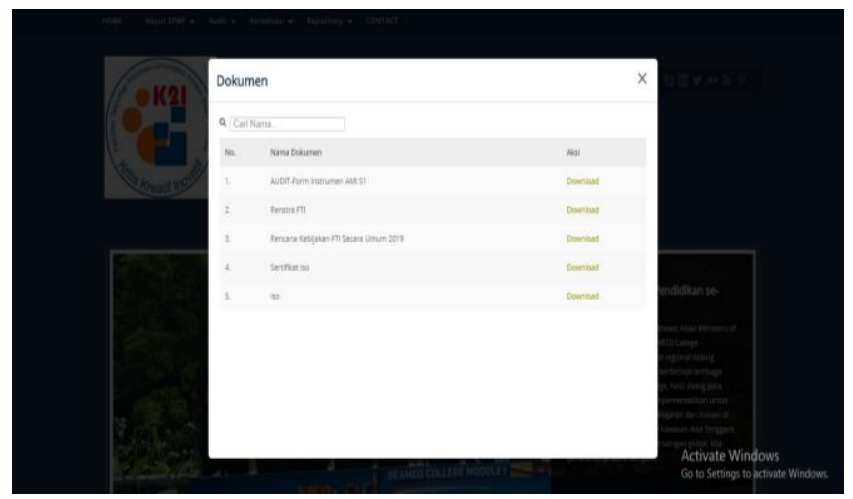

Gambar 4. Pengarsipan Dokumen 
Pada Gambar 4 merupakan menu terdapat dalam repository dokumen. Dimana ketika user akan melakukan pencarian dokumen, user akan disediakan fitur pencarian bedasarkan keyword. Jika keyword yang di input sesuai dengan isi file maka data yang ada pada sistem akan menampikan data yang dicari. User juga dapat melakukan pengunduhaan dokumen.

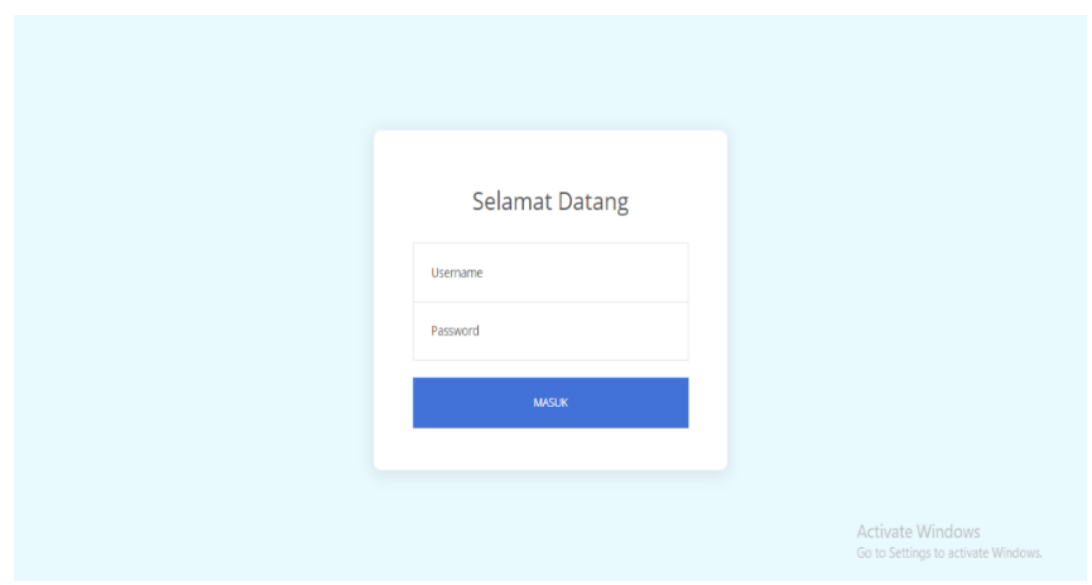

Gambar 5. halaman Login admin

Pada Gambar 5 merupakan tampilan awal login yang hanya ditujukan pada Admin. Agar login berhasil atau valid maka Username dan Password harus sesuai. Jika Username dan Password tidak sesuai maka login akan invalid yang dimana user akan di kembalikan kehalaman login seperti semula.

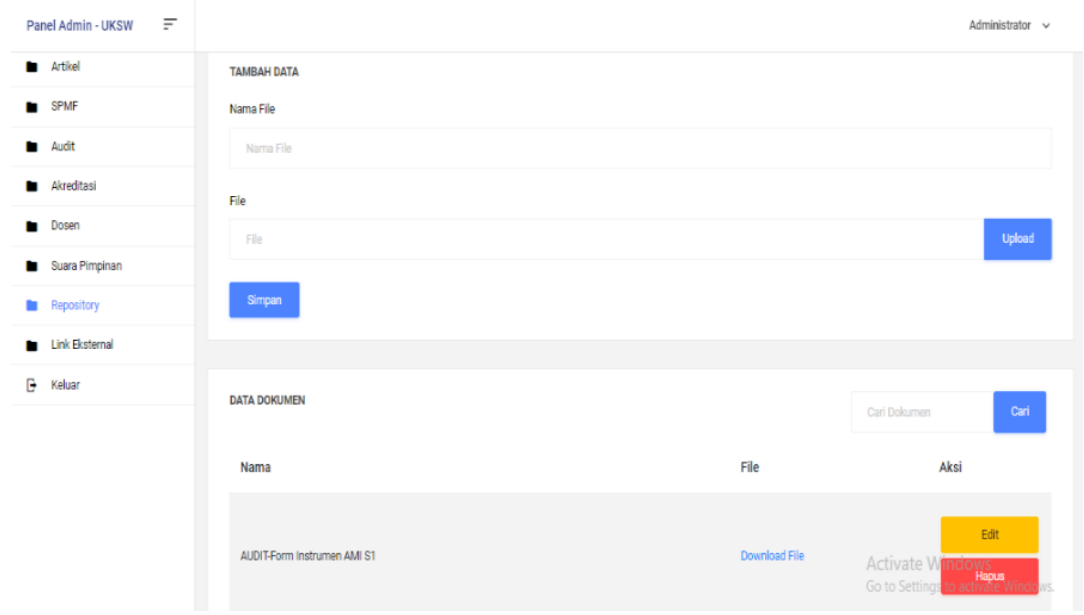

Gambar 6. Tampilan Panel Admin 
Pada Gambar 6 merupakan tampilan admin. Dimana admin dapat mengubah serta menambahkan, dan menghapus file yang ada pada web.

Kode Program 1. Fungsi pencarian dokumen pada halaman pengguna

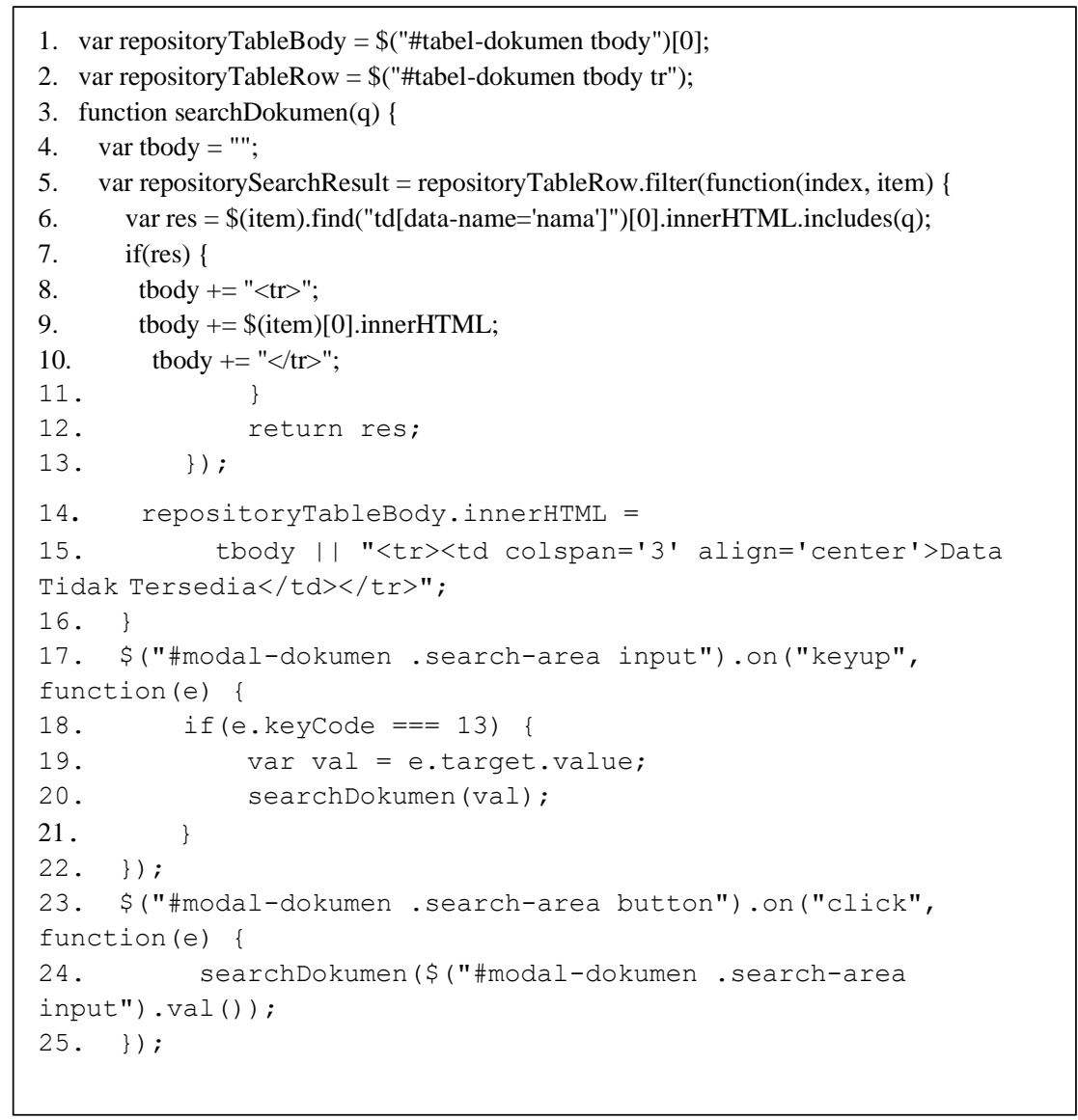

Kode program 1 merupakan fungsi untuk pencarian dokumen pada halaman pengguna. Pada awal nya data dokumen yang telah dihasilkan atau diambil dari database itu tampilkan pada sebuah tabel dokumen. Baris ke-3 hingga 16 ialah fungsi pencarian dokumen yang memiliki parameter ' $q$ ' sebagai nilai yang ingin dicari. Baris ke-5 hingga 13 menunjukan proses filterisasi nama dokumen terkait. Dan baris ke-14 dan 15 ialah proses penyisipan konten HTML untuk memperbarui isi dari tabel dokumen. Sedangkan baris ke-17 hingga 22 dan baris ke-23 hingga 25 adalah sebuah event untuk menanggulangi proses pencarian dokumen. 
Kode Program 2 Pengunduhan dokumen pada halaman pengguna

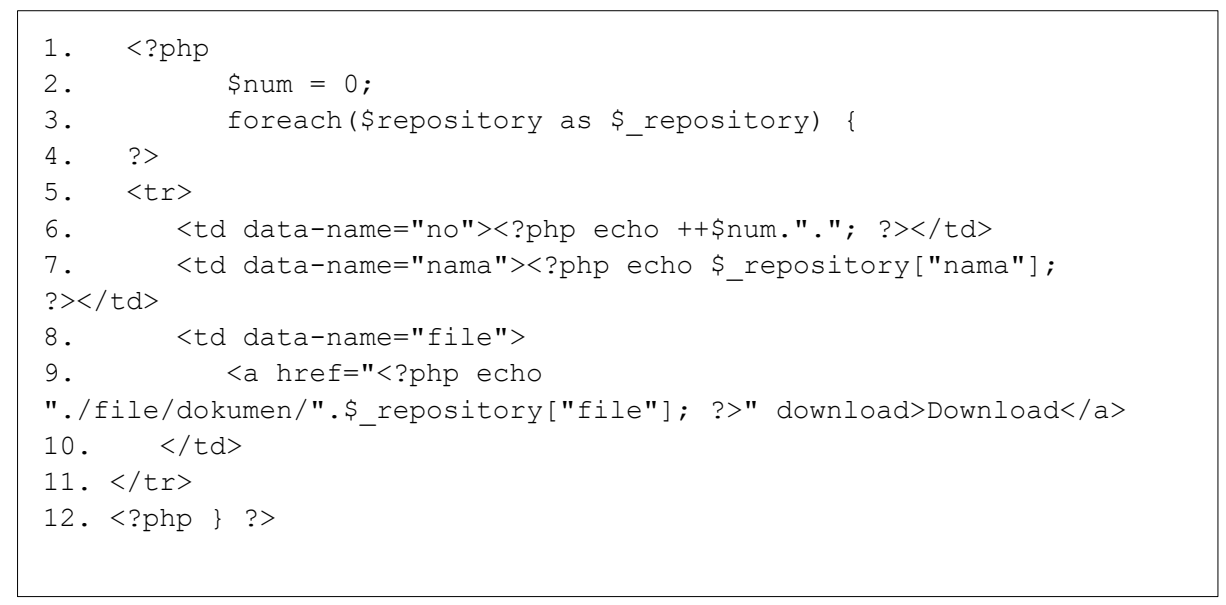

Kode Program 2 jika dilihat dari baris ke-1 hingga 12 itu ialah proses ditampilkannya data dokumen dalam sebuah tabel. Dan \$repository ialah variabel berupa array yang menampung data dokumen. Proses pengunduhan dokumen terjadi pada baris ke-9, yakni itu ialah sebuah link yang merujuk ke lokasi dari tempat dokumen tersimpan dan link tersebut memiliki atribut download agar pada saat pengguna klik link tersebut, maka file yang terkait akan otomatis terunduh.

Kode Program 3. Fungsi login untuk pengaksesan panel admin

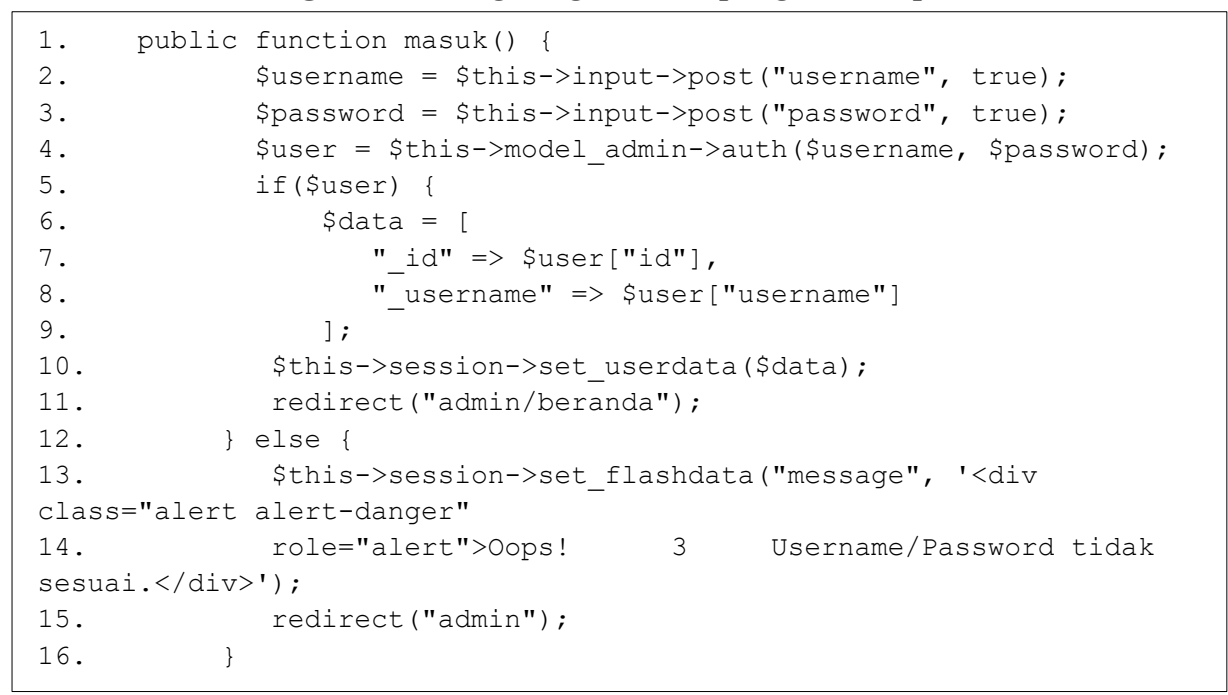

Kode Program 3 ialah sebuah fungsi penangan proses login untuk pengaksesan panel admin. Baris ke-2 dan 3 ialah proses penugasan pada variabel untuk 
menampung inputan pengguna terkait username dan password. Sedangkan baris ke-4 ialah proses penugasan pada variabel untuk menampung hasil dari pencocokan username dan password yang telah dilakukan. Dan baris ke-5 hingga 16 ialah proses pengkondisian terhadap variabel user dan juga mencakup hal yang perlu dilakukan jika variabel user bernilai 'true' maupun 'false

\subsection{Evaluation}

Sistem yang dibangun dalam pengeleloaan pengetahuan dengan menerapkan konsep Knowledge Management System sudah sesuai dengan kebutuhan lembaga tersebut. Pengujian sistem menggunakan teknik pengujian blackbox.Apakah sudah berjalan dengan baik atau terdapat kesalahan/bug. Hasil pengujian blackbox akan dijukan pada tabel 1.[10]

Tabel 1. Hasil Pengujian blackbox

\begin{tabular}{|c|c|c|c|c|}
\hline $\begin{array}{l}\text { Fungsi } \\
\text { yang diuji }\end{array}$ & Kondisi & $\begin{array}{l}\text { Output yang } \\
\text { diharapkan }\end{array}$ & $\begin{array}{l}\text { Output yang } \\
\text { dihasilkan } \\
\text { sistem }\end{array}$ & $\begin{array}{l}\text { Status } \\
\text { Pengujian }\end{array}$ \\
\hline \multirow[t]{2}{*}{ Log-gin } & $\begin{array}{l}\text { User-name } \\
\text { dan pass-word } \\
\text { benar }\end{array}$ & $\begin{array}{l}\text { Menam- } \\
\text { pilkan bagian } \\
\text { adminis-trator }\end{array}$ & $\begin{array}{l}\text { Menam- } \\
\text { pilkan bagian } \\
\text { adminis-trator }\end{array}$ & Valid \\
\hline & $\begin{array}{l}\text { User-name } \\
\text { dan password } \\
\text { salah }\end{array}$ & $\begin{array}{l}\text { Gagal } \\
\text { menampilan } \\
\text { bagian adminis- } \\
\text { trator }\end{array}$ & $\begin{array}{l}\text { Gagal me- } \\
\text { nampilkan } \\
\text { bagian } \\
\text { adminis-trator }\end{array}$ & Valid \\
\hline $\begin{array}{l}\text { Edit data } \\
\text { anggota }\end{array}$ & $\begin{array}{l}\text { Pilih salah } \\
\text { satu data } \\
\text { anggota }\end{array}$ & $\begin{array}{l}\text { Berhasil ubah } \\
\text { data anggota }\end{array}$ & $\begin{array}{l}\text { Berhasil ubah } \\
\text { data anggota }\end{array}$ & Valid \\
\hline $\begin{array}{l}\text { Hapus data } \\
\text { ang-gota }\end{array}$ & $\begin{array}{l}\text { Pilih salah } \\
\text { satu data } \\
\text { karyawan }\end{array}$ & $\begin{array}{l}\text { Berhasil hapus } \\
\text { data anggota }\end{array}$ & $\begin{array}{l}\text { Berhasil } \\
\text { hapus data } \\
\text { anggota }\end{array}$ & Valid \\
\hline $\begin{array}{l}\text { Update data } \\
\text { anggota }\end{array}$ & $\begin{array}{l}\text { Pilih salah } \\
\text { satu data } \\
\text { anggota }\end{array}$ & $\begin{array}{l}\text { Berhasil } \\
\text { perbaharui data } \\
\text { anggota }\end{array}$ & $\begin{array}{l}\text { Berhasil } \\
\text { perbaharui } \\
\text { data anggota }\end{array}$ & Valid \\
\hline
\end{tabular}


Vol. 3, No. 1, March 2021

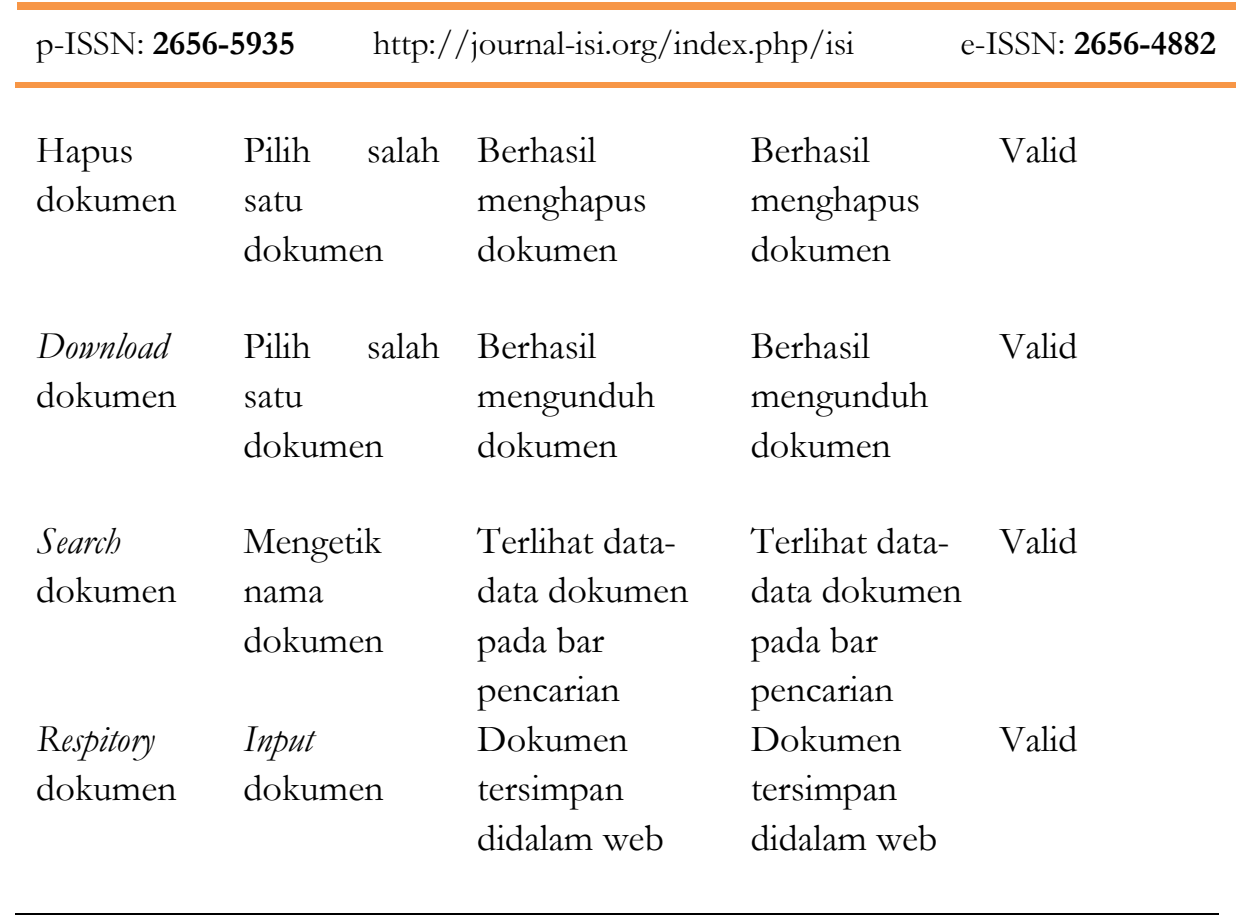

\section{KESIMPULAN}

Knowledge Management adalah usaha untuk meningkatkan pengetahuan yang berguna dalam organisasi, diantaranya membiasakan budaya berkomunikasi antar anggota, memberikan kesempatan untuk belajar, serta saling berbagi knowledge sehingga menghasilkan knowledge yang baru atau memperbaharui knowledge yang ada. Sistem Informasi PMF menjadi bagian tak terpisahkan dari Mutu sebuah Fakultas. Karena itu perlu adanya sistem informasi yang dirancang yang sesuai dengan visi FTI UKSW. Pembuatan Sistem Informasi berbasis Web merupakan sistem yang dapat diakses dimana dan kapan saja.

\section{DAFTAR PUSTAKA}

[1] D. P. D. Widowati, "Inilah Peringkat E-Government Indonesia Berdasarkan Survei PBB 2016," www.bpptik.kominfo.go.id, 2016. .

[2] A. W. Pearson, N. Vaughan, and J. Butler, "The implementation of TQM in R\&D," Int. J. Technol. Manag., vol. 16, no. 4-6, pp. 405-432, 1998, doi: 10.1504/ijtm.1998.002679.

[3] W. Kurnia Sari, K. Ditha Tania, and J. Sistem Informasi Fasilkom Unsri, "Penerapan Knowledge Management System (KMS) Berbasis Web Studi Kasus Bagian Teknisi dan Jaringan Fakultas Ilmu Komputer Universitas Sriwijaya," J. Sist. Inf., vol. 6, no. 2, pp. 2355-4614, 2014, [Online]. Available: http:/ / ejournal.unsri.ac.id/index.php/jsi/index. 
[4] C. A. Suprapto and S. Assegaff, "Analisis Dan Perancangan Knowledge Management System Pada Sma Negeri 6 Kota Jambi," J. Manaj. Sist. Inf., vol. 3, no. 3, pp. 973-988, 2018.

[5] C. McInerney, "Knowledge management and the dynamic nature of knowledge," J. Am. Soc. Inf. Sci. Technol., vol. 53, no. 12, pp. 1009-1018, 2002, doi: 10.1002/asi.10109.

[6] N. P. Ayudhana, L. Andrawina, and A. Musnansyah, "Perancangan dan Pembangunan Knowledge Management System pada Modul Pengabdian Masyarakat dan Penunjang Menggunakan Framework CodeIgniter dengan Metode Iterative Incremental," e-Proceeding Eng., vol. 2, no. 2, pp. 57665773, 2015.

[7] R. Ramadi, "Penerapan Knowledge Management System Pada Perusahaan Otomotif: Studi Kasus Pt. Astrido Jaya Mobilindo," Simetris J. Tek. Mesin, Elektro dan Ilmu Komput., vol. 7, no. 2, p. 635, 2016, doi: 10.24176/simet.v7i2.776.

[8] Y. Akbar, "Knowledge Management System pada Biro Administrasi Akademik Akademi Pariwista Nusantara," STRING (Satuan Tulisan Ris. dan Inov. Teknol., vol. 3, no. 1, p. 87, 2018, doi: 10.30998/string.v3i1.2734.

[9] Y. Sonatha, I. Rahmayuni, A. Alanda, and I. Saputra, "Rancang Bangun Aplikasi Knowledge Management Berbasis Web," INVOTEK J. Inov. Vokasional dan Teknol., vol. 18, no. 2, pp. 133-140, 2018, doi: 10.24036/invotek.v18i2.423.

[10] P. Purwantoro, Y. Umaidah, and U. Enri, "Penerapan Knowledge Management System Berbasis Informasi Desa Untuk Meningkatkan Layanan Publik Desa Dukuh Karya," J. Techno Nusa Mandiri, vol. 15, no. 2, p. 121, 2018, doi: 10.33480/techno.v15i2.912.

[11] W. Kurnia Sari, K. Ditha Tania, and J. Sistem Informasi Fasilkom Unsri, "Penerapan Knowledge Management System (KMS) Berbasis Web Studi Kasus Bagian Teknisi dan Jaringan Fakultas Ilmu Komputer Universitas Sriwijaya," J. Sist. Inf., vol. 6, no. 2, pp. 2355-4614, 2014.

[12] P. M. Ramdani, "Pengembangan Knowledge Management System Berbasis Knowledge Audit," J. Inform., vol. 5, no. 1, pp. 145-156, 2018, doi: 10.31311/ji.v5i1.2522. 